\title{
PENGARUH PENGGUNANAN MODEL DEBAT (DEBATE) TERHADAP KEMAMPUAN MENULIS PARAGRAF ARGUMENTASI PADA SISWA KELAS X SMK SWASTA SULTAN ISKANDAR MUDA TAHUN PELAJARAN 2018/2019
}

\author{
Ayu Trigustina Panjaitan ${ }^{1}$, Annisa ${ }^{2}$, Dani Sukma Agus Setiawan ${ }^{3}$ \\ Universitas Prima Indonesia ${ }^{1}$, Universitas Prima Indonesia ${ }^{2}$, Universitas Prima Indonesia ${ }^{3}$ \\ Pos-el: trigustinaayu@gmail.com ${ }^{1}$,rindi.nisa48@gmail.com², \\ danisukmaagussetiawan@unprimdn.ac.id ${ }^{3}$
}

\begin{abstract}
ABSTRAK
Tujuan yang ingin dicapai dalam penelitian ini adalah untuk mengetahui pengaruh penggunaan model debat (debate) terhadap kemampuan menulis paragraf argumentasi siswa kelas X SMK Swasta Sultan Iskandar Muda Tahun Pelajaran 2018/2019. Penelitian ini menggunakan metode kuantitatif Eksperimen dengan desain two group post-test design only. Adapun populasi dalam penelitian ini adalah seluruh siswa kelas X SMK Swasta Sultan Iskandar Muda yang berjumlah 102 siswa. Sampel Penelitian terdiri dari dua kelas, satu kelas sebagai kelas kontrol yaitu kelas X-MM 1 sejumlah 31 siswa dan satu kelas sebagai kelompok eksperimen yaitu X-MM 2 sejumlah 31 siswa. Pengambilan sampel ini dengan random sampling ( acak kelas ). Teknik pengumpulan data dengan menggunakan tes, yaitu post-test. Proses pengumpulan data dengan cara menugaskan siswa menulis Paragraf Argumentasi. Sebelum dilakukan analisis data, terlebih dahulu dilakukan uji normalitas dan uji homogenitas yang menunjukkan bahwa skor post-test berdistribusi normal dan homogen. Teknik analisis data adalah uji-t. Hasil penelitian menunjukan adanya perbedaan kemampuan menulis paragraf argumentasi pada siswa kelas X SMK Swasta Sultan Iskandar Muda dengan penggunaan model debat (debate) dan tanpa penggunaan model debat (debate. Perbedaan tersebut ditunjukan oleh hasil uji-t yaitu $-\mathrm{t}_{\text {tabel }}=-2,00<\mathrm{t}_{\text {hitung }}=5,83>\mathrm{t}_{\text {tabel }}=2,00$, maka hipotesis nol $\left(\mathrm{H}_{0}\right)$ ditolak dan Hipotesis alternatif $\left(\mathrm{H}_{\mathrm{a}}\right)$ diterima. Hal ini dibuktikan bahwa terdapat pengaruh positif penggunaan model debat (debate) terhadap kemampuan menulis paragraf argumentasi pada siswa kelas X SMK Swasta Sultan Iskandar Muda Tahun Pelajaran 2018/2019.
\end{abstract}

Kata Kunci: Debat (Debate), Paragraf Argumentasi, Eksperimen.

\section{ABSTRACT}

Objectives to be achieved in research This is to find out the effect of using the debate model on the ability to write paragraph arguments in class X Sultan Iskandar Muda Private Vocational School 2018/2019 Academic Year. This research uses quantitative methods Experiments with two group design post-test design only. The population in this study were all students of class X of Sultan Iskandar Muda Private Vocational School totaling 102 students. The research sample consisted of two classes, one class as a control class, namely the X-MM 1 class, 31 students and one class as the experimental group, namely X-MM 2, 31 students. This sample was taken by class random sampling. Data collection techniques using tests, namely post test. The process of collecting data by assigning students to write the Argument Paragraph. Before the data analysis was carried out, the normality test and homogeneity test were first performed which showed that the post-test score was normally distributed and homogeneous. The data analysis technique is the t-test. The results showed that there was a difference in the ability to write arguments paragraphs in Sultan Iskandar Muda's 11th grade students with the use of a debate model and without the use of a debating model (debate. The difference was 


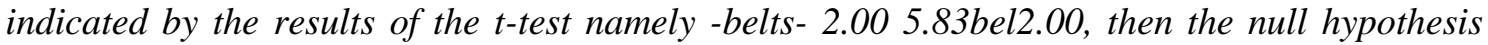
(Ho) is rejected and the alternative Hypothesis ( $H$ is accepted. Ha is proven that there is a positive influence on the use of debate models on the ability to write paragraph arguments in class X Sultan Iskandar Muda Vocational School 2018 Academic Year / 2019.

\section{Keywords: Debate, Arguments Paragraph, Experiment.}

\section{PENDAHULUAN}

Keterampilan berbahasa ada empat bagian, yaitu: keterampilan berbicara, menyimak, membaca dan menulis. Seiring dengan perkembangan teknologi yang semakin canggih, keempat keterampilan ini memegang peranan yang sangat penting. Salah satu keterampilan yang sangat berpengaruh di era globalisasi saat ini adalah keterampilan menulis.

Tarigan (2013:3) mengatakan "Menulis merupakan suatu kegiatan yang produktif dan ekspresif". Akan tetapi, keterampilan ini tidak dapat diperoleh secara alamiah. Keterampilan menulis tersebut harus dipelajari dan dilatih sungguh-sungguh dan dibekali dengan keterampilan berbahasa lainnya seperti keterampilan membaca dan menyimak dengan latihan yang cukup sehingga menghasilkan tulisan yang efektif yang diungkapkan dalam bentuk paragraf atau karangan. Morsey dalam Guntur Tarigan (2013: 4) mengatakan "menulis

dipergunakan,melaporkan/memberitahuk an,mempengaruhi; dan serta tujuan seperti itu hanya dapat dicapai dengan baik oleh orang - orang yang dapat menyusun pikirannya dan mengutarakannya dengan jelas, kejelasan ini bergantung pada pikiran, organisasi, pemakaian kata-kata, dan struktur kalimat".

Menurut Kuntarto dalam Dalman (2008:53),"Paragraf adalah bagian karangan yang terdiri dari atas beberapa kalimat yang berkaitan utuh dan serta membentuk satu kesatuan pikiran". Salah satu wadah bahasa tulisan adalah paragraf, Maka paragraf merupakan pernyataan gagasan atau ide yang bersumber dari pengalaman, pengamatan, imajinasi, pendapat, dan keyakinan dengan menggunakan media tulis sebagai alatnya. Paragraf dapat dibedakan menjadi lima jenis, yaitu paragraf narasi, eksposisi, persuasi, argumentasi dan deskripsi. Dalam hal ini peneliti memilih paragraf argumentasi. Menurut Yanti dkk (2017: 83), "Paragraf Argumentasi merupakan paragraf yang bertujuan untuk meyakinkan atau memengaruhi pembaca agar menerima pendapat penulis". Maka Paragraf argumentasi itu penulis dapat berfikir kritis dan logis serta mau menerima orang lain sebagai bahan pertimbangan. Keterampilan menulis juga dapat digunakan untuk mencatat, merekam, meyakinkan, melaporkan, menginformasikan, dan mempengaruhi pembaca. Maksud dan tujuan seperti itu hanya dapat dicapai dengan baik oleh para siswa yang dapat menyusun dan merangkai jalan pikiran serta mengemukakan secara tertulis, lancar dan komunikatif. Dengan penguasaan keterampilan menulis, diharapkan siswa dapat mengungkapkan gagasan, pikiran, dan perasaan yang dimilikinya. Dengan demikian, segala informasi, ilmu pengetahuan dan berbagai kecakapan yang diperoleh siswa dalam pembelajaran tidak hanya sekadar hafalan yang mudah dilupakan sesaat setelah menjalani tes.

Keterampilan menulis merupakan salah satu keterampilan yang sering mendapatkan nilai terendah diantara keterampilan yang lainnya. Sehingga menarik perhatian banyak orang untuk lebih mengetahui apa 
penyebab keterampilan menulis pada umumnya sangat rendah. Beberapa alasan tentang rendahnya kemampuan siswa dalam menulis diantaranya: a) rendahnya minat menulis, b) Sebagian besar siswa membutuhkan waktu yang cukup lama untuk dapat menuangkan ide dan gagasannya, c) siswa kurang biasa mengembangkan bahasanya d) kurangnya inovasi guru untuk menciptakan metode pembelajaran yang menarik.

Kemampuan menulis yang rendah dapat dilihat dari penguasaan unsur pengetahuan yang digunakan siswa pada saat belajar. Unsur menulis yang dimaksud seperti kurangnya pengetahuan tentang menulis paragraf argumentasi ataupun berpendapat. Hal ini dapat terlihat dari ketika seorang siswa disuruh untuk menuangkan pendapat di depan kelas. Kurangnya kemampuan siswa belajar menjadi salah satu penghambat untuk menciptakan kemampuan menulis siswa yang berkualitas. Siswa beranggapan bahwa pelajaran bahasa Indonesia sering dianggap sulit untuk dipelajari dan seakan siswa beranggapan bahwa pelajaran bahasa Indonesia tidak begitu penting dibandingkan dengan pelajaran lainnya. Selain dari kemampuan menulis siswa yang rendah, faktor penghambat siswa senang menulis adalah teks yang ditulis tidak sesuai dengan keinginan hati. Dalam faktor ini, seakan siswa diharuskan menulis tentang apa yang diinginkan oleh gurunya, dan itu yang akan membuat kemalasan siswa dalam membaca itu meningkat. Seharusnya peserta didik dibiarkan menulis apa yang diinginkan peserta didik tersebut, dan kita sebagai tenaga pendidik akan menghubungkan apa yang ditulis peserta didik dengan materi pembelajaran. Selain dari kemampuan siswa yang rendah, metode pembelajaran di kelas bersifat konvensional yang menyebabkan siswa terpaku pada teori. Model pembelajaran konvensional membuat siswa tidak memiliki peranan yang banyak. Mereka sering kali menjadi penonton ketika guru menjelaskan materi pembelajaran dan tidak memiliki ruang untuk mengembangkan kreativitasnya.

Hal senada juga diungkapkan oleh guru sekolah tersebut bahwa kemampuan siswa dalam menulis argumentasi itu semakin berkurang. Salah satu inovasi dari sang peneliti yang dapat dilakukan dalam melatih kemampuan menulis argumentasi siswa yaitu dengan model Debat (debate )termasuk salah satu model untuk menentukan baik tidaknya suatu usul tertentu yang didukung oleh satu pihak yang disebut pendukung. Istarani (2017:3) menyatakan "Model debat merupakan penyampaian materi ajar dengan meninjau dari dua sisi yaitu pro dan kontra untuk menjadi kebenaran dari peristiwa yang ada". Maka Model debat merupakan salah satu model pembelajaran yang sangat penting untuk meningkatkan kemampuan akademik siswa. Oleh karena itu, model pembelajaran ini cocok diterapakan seorang guru agar siswa lebih aktif dalam proses pembelajaran untuk mengembangkan keterampilan menulis, karena didalam model ini, siswa diberi tugas oleh guru Laura Mayasari untuk membentuk kelompok secara heterogen, dan siswa terlibat secara langsung dalam kelompok. Berdasarkan pemaparan tersebut, peneliti akan mengkaji "Pengaruh Penggunaan Model Debat (debate) Terhadap Kemampuan Menulis Paragraf Argumentasi Pada Siswa Kelas X Smk Swasta Sultan Iskandar Muda Medan Tahun Pembelajaran 2018/2019”.

\section{METODE PENELITIAN}

Jenis penelitian ini adalah penelitian kuantitatif dengan menggunakan metode eksperimen. Dikatakan metode eksperimen karena penelitian tersebut salah satu cara untuk mencari hubungan sebab akibat antara 
dua faktor yang sengaja ditimbulkan oleh penelitian dengan mengeliminisasi atau mengurangi atau menyisihkan faktor - faktor lain yang mengganggu ( Arikunto 2010:9 ).

Penelitian ini dilakukan untuk mengetahui ada atau tidaknya pengaruh penggunaan model debat (debate) terhadap kemampuan menulis paragraf argumentasi siswa kelas X SMK Swasta Iskandar Muda tahun pelajaran 2018/2019. Instrumen yang digunakan dalam penelitian ini adalah tes uraian dengan memberikan post-test terhadap kelas eksperimen dan kelas kontrol yang sudah terpilih dan sudah menerima perlakuan pembelajaran yang berbeda. Kelas eksperimen adalah kelas yang diajar dengan model debat (debate), sedangkan kelas kontrol adalah kelas tanpa menggunakan model debat (debate).

\section{HASIL DAN PEMBAHASAN}

Hasil Post-test Kelas Kontrol

\begin{tabular}{|c|c|c|c|c|c|}
\hline \multicolumn{5}{|c|}{ Hasil Post-test Kelas Kontrol } \\
\hline No & Nilai & Frekuensi & $S_{1}$ & $S_{2}^{2}$ & $\bar{X}_{1}$ \\
\hline 1 & 50 & 3 & & & \\
\hline 2 & 55 & 4 & \multirow{3}{*}{6,54} & \multirow{4}{*}{42,81} & \multirow{2}{*}{61,79} \\
\hline 3 & 60 & 6 & & & \\
\hline 4 & 65 & 13 & & & \\
\hline 5 & 70 & 4 & & & \\
\hline 6 & 75 & 1 & & \\
\hline
\end{tabular}

Dari tabel tersebut maka dapat diketahui rata-rata untuk kelas kontrol adalah 61,79, standar deviasi 6,54 dan varians 42,81. Skor tertinggi terdapat pada kelas kontrol tanpa menggunakan model adalah 75. Selanjutnya untuk data kelas eksperimen dapat dilihat dalam tabel berikut ini:

\section{Hasil Post-test Kelas Eksperimen}

\begin{tabular}{|c|c|c|c|c|c|}
\hline \multicolumn{6}{|c|}{ Hasil Post-test Kelas Eksperimen } \\
\cline { 1 - 3 } No & Nilai & Frekuensi & $S_{1}$ & $S_{2}^{1}$ & $\bar{X}_{1}$ \\
\hline 1 & 50 & 2 & & & \\
\hline 2 & 55 & 1 & & & \\
\cline { 1 - 3 } 3 & 60 & 1 & \multirow{2}{*}{9,78} & \multirow{2}{*}{95,69} & \multirow{2}{*}{73,40} \\
\cline { 1 - 3 } 4 & 65 & 2 & & & \\
\cline { 1 - 3 } 5 & 70 & 8 & & & \\
\hline 6 & 75 & 8 & & & \\
\hline 7 & 80 & 3 & & & \\
\hline 8 & 85 & 4 & & & \\
\hline
\end{tabular}

\begin{tabular}{|l|c|c|c|c|c|}
\hline 9 & 90 & 2 & & & \\
\hline \multicolumn{5}{|c|}{ Dari tabel tersebut maka dapat } \\
\hline
\end{tabular} diketahui rata - rata untuk kelas eksperimen adalah 73,40, standar deviasi 9,78 dan varians 95,69. Skor tertinggi terdapat pada kelas eksperimen 90.

Dari pemerolehan rata - rata kedua kelas dapat dibandingkan melalui grafik berikut :

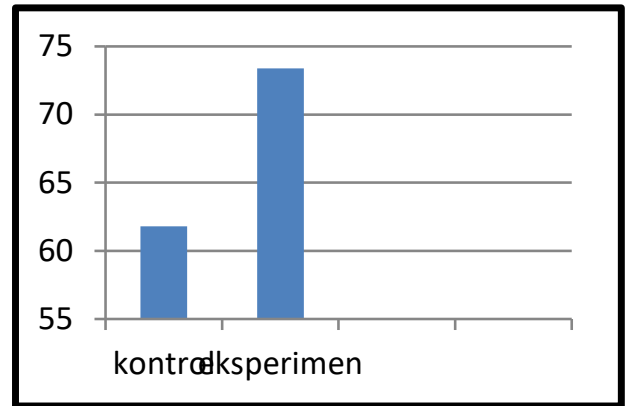

Kemudian untuk uji normalitas didapatkan hasil perhitungan sebagai berikut :

Uji Normalitas Data dengan Uji Lilifors

\begin{tabular}{|c|c|c|c|c|c|}
\hline No & Data & Kelas & $L_{0}$ & $L_{\text {tabel }}$ & $\begin{array}{c}\text { Kesim } \\
\text { pulan }\end{array}$ \\
\hline 1 & $\begin{array}{c}\text { Post }- \\
\text { test }\end{array}$ & Kontrol & 0,1421 & 0,159 & Normal \\
\hline 2 & $\begin{array}{c}\text { Post }- \\
\text { test }\end{array}$ & $\begin{array}{c}\text { Eksperi } \\
\text { men }\end{array}$ & 0,1464 & 0,159 & Normal \\
\hline
\end{tabular}

Maka dapat dilihat bahwa dari tabel tersebut hasil Post-test kelas kontrol diperoleh $L_{\text {hitung }}<L_{\text {tabel }}$ yakni $0,1421<0,159$ dan hasil Post-test kelas eksperimen diperoleh $\quad L_{\text {hitung }}<$ $L_{\text {tabel }}$ yakni $0,1464<0,159$. Dengan demikian kedua data menerima kriteria pengujian bahwa sampel berasal dari populasi berdistribusi Normal.

Selanjutnya pengolahan data dilakukan dengan mencari tahu apakah data hasil menulis Paragraf argumentasi pada kelas homogen atau tidak. Berdasarkan perhitungan yang sudah dilakukan maka dapat hasilnya, data Post-test kelas kontrol diperoleh varians $=42,81$ dan data Post-test kelas eksperimen diperoleh varians $=$ 95,69. Oleh karena itu, kedua sampel 
diperoleh pengujian Maka, $\mathrm{F}_{\text {hitung }}<\mathrm{F}_{\text {tabel }}$ yakni $1,49<1,84$ maka hal ini membuktikan bahwa sampel dari populasi yang homogen. Hal ini menunjukkan bahwa persyaratan analisi dalam penelitian ini terpenuhi, sehingga dapat dilanjutkan pada pengujian hipotesis dengan uji " $\mathrm{t}$ " dengan perhitungan sebagai berikut :

\section{Uji Hipotesis}

\begin{tabular}{|c|c|c|c|c|c|}
\hline No & Data & $\begin{array}{l}\text { Nilai } \\
\text { rata- } \\
\text { rata }\end{array}$ & $t_{\text {hitung }}$ & $t_{\text {tabel }}$ & Kesimpulan \\
\hline \multirow[t]{2}{*}{1} & $\begin{array}{c}\text { Post- } \\
\text { test } \\
\text { kontr } \\
\text { ol }\end{array}$ & $\begin{array}{c}61,7 \\
9\end{array}$ & \multirow{2}{*}{5,83} & \multirow{2}{*}{2,00} & \multirow[t]{2}{*}{$\begin{array}{l}\text { Ada pengaruh } \\
\text { yang signifikan }\end{array}$} \\
\hline & $\begin{array}{c}\text { Post- } \\
\text { test } \\
\text { eksp } \\
\text { erim } \\
\text { en }\end{array}$ & $\begin{array}{c}73,4 \\
0\end{array}$ & & & \\
\hline
\end{tabular}

Berdasarkan perhitungan yang telah dilakukan, maka dapat diketahui bahwa Maka, $t_{\text {hitung }}>t_{\text {tabel yakni }}$ 5,83 $>$ 2,00 dengan demikian, hipotesis nihil $\left(\mathrm{H}_{0}\right)$ ditolak dan hipotesis alternatif $(\mathrm{Ha})$ diterima. Sehingga dapat disimpulkan bahwa model debat (debate) memiliki pengaruh terhadap kemampuan menulis paragraf argumentasi siswa kelas $\mathrm{X}$ SMK Swasta Sultan Iskandar Muda Tahun Pelajaran 2018/2019.

\section{SIMPULAN}

Berdasarkan hasil penelitian yang dipaparkan pada bab sebelumnya dapat disimpulkan bahwa mite dapat ditransformasikan menjadi naskah drama serta bisa dijadikan sebagai bahan ajar Bahasa Indonesia pada siswa SMP kelas VIII.

Berdasarkan hasil penelitian, maka dapat disimpulkan bahwa :

a. Kemampuan siswa kelas X SMK Swasta Sultan Iskandar Muda Tahun Pelajaran 2018/2019 dalam menulis pantun dengan tanpa adanya Penggunaan Model Debat dapat dikategorikan cukup dengan nilai rata-rata 61,79 .

b. Kemampuan siswa kelas X SMK Swasta Sultan Iskandar Muda Tahun Pelajaran 2018/2019 dalam menulis Paragraf Argumentasi dengan penggunaan model debat dapat dikategorikan baik dengan nilai ratarata 73.40.

c. Penggunaan Model Debat memiliki pengaruh yang signifikan terhadap kemampuan menulis paragraf argumentasi daripada tanpa penggunaan model debatpada siswa kelas siswa kelas X SMK Swasta Sultan Iskandar MudaTahun Pelajaran 2018/2019. Hal ini dibuktikan dari hasil perbandingan nilai rata-rata antara dengan adanya penggunaan model debat dengan tanpa adanya penggunaan model debat yakni, nilai rata-rata kelas eksperimen 73.40 sedangkan nilai rata-rata kelas kontrol 61,79 . Selain itu, dapat juga dilihat dari hasil uji " $t$ " diperoleh $\mathrm{t}_{\text {hitung }}>\mathrm{t}_{\text {tabel }}$ yaitu 5,83 > 2,00. Maka,hipotesis nol $\left(\mathrm{H}_{0}\right)$ ditolak dan Hipotesis alternatif $\left(\mathrm{H}_{\mathrm{a}}\right)$ diterima.

Berdasarkan kesimpulan di atas dan hasil pengamatan selama proses penelitian berlangsung, peneliti mengemukakan beberapa saran sebagai berikut :

a. Kemampuan menulis paragraf argumentasi perlu ditingkatkan lagi. Hal tersebut tentunya memerlukan berbagai strategi dan teknik serta adanya Penggunaan Model Debatagar siswa tidak bosan dalam belajar menulis khususnya menulis Paragraf Argumentasi.

b. Sebagai bahan masukan bagi mahasiswa (peneliti lain) yang ingin melakukan penelitian dengan fokus permasalahan yang sama.

c. Perlu dilakukan penelitian lanjutan agar memberikan masukan yang bersifat membangun bagi dunia pendidikan khususnya dalam 
meningkatkan kemampuan siswa dalam menulis paragraf Argumentasi.

\section{DAFTAR PUSTAKA}

Akhadiah, Sabarti. 1997. Pembinaan Kemampuan Menulis Bahasa. Jakarta: Erlangga.

Barus, Sanggup. 2010. Pembinaan Kompetensi Menulis. Medan: USU Press.

Dalman. 2015. Keterampilan Menulis. Jakarta: Rajagrafindo Persada.

Dina. 2018. Jurnal. " Peningkatan Kemampuan Menulis Paragraf Argumentasi dengan menggunakan Model pembelajaran Gambar Berseripada siswa kelas $X$ SMA Swasta Setia Budi Binjai" Universitas Prima Indonesia.

Eliza. 2012. Jurnal. "Efektivitas Metode Pembelajaran Aktif Tipe Learning Start With A Question Terhadap Kemampuan Menulis Paragraf Argumentasi Oleh Siswa Kelas X SMA Swasta DR. Wahidin Sudirohusodo Medan" Universitas Medan.

Erni Fatmawati, Imron. 2017. Jurnal. "Pengaruh Metode Pembelajaran Debat Aktif Terhadap Hasil Belajar Siswa Sman 1 Belitang Hilir" Universitas Pancasakti Tegal. Vol 11, No 2

Handayani, dkk. 2015. Bahasa dan Sastra Indonesia 1. Jakarta: Grafindo.

Istarani. 2015. 58 Model Pembelajaran Inovatif. Medan: Media Persada.

Poerwadarminta. 1998. Kemampuan Menggunakan Bahasa Lisan dan Tulisan. Jakarta: Rineka Cipta.

Siluh Putu. 2013. Jurnal. "Penerapan Teknik Debat Dalam Pembelajaran Menulis Untuk Meningkatkan Kemampuan Menulis Argumentasi Siswa Kelas X.1 Sma Negeri 2 Banjar" Universitas Pendidikan Ganesha. Vol 1, No 5
Sugiono. 2013. Metode Penelitian Kuantitatif, Kualitatif, dan R\&D. Bandung: CV, Alfabeta.

Sudjana. 2016: Metoda Statistika, Bandung: Tarsito.

Tarigan, Henry Guntur . 2013. Menulis. Sebagai Suatu Keterampilan Berbahasa. Bandung: Pencetakan Angkasa.

Vera. 2018. "Penggunaan Model Pembelajaran Inkuiri untuk Meningkatkan Keterampilan Menulis Paragraf Argumentasi Siswa Kelas X-1 SMA Swasta Tiga Putra Persada Tahun Pelajaran 2017/2018”, Universitas Prima Indonesia. Medan.

Yanti dkk, 2017. Bahasa Indonesia konsep dasar dan penerapan. Jakarta : PT Grasindo, Anggota IKAPI 